\title{
Nutritional Status and Health-Related Quality of Life Among Elderly in Rural Area in Egypt.
}

\author{
Sara A. Hamzal, Samia A. Abdul-Rahman', Asmaa M. Nabiel', Ahmed S. Sedky².
}

1 Geriatric Medicine \& Gerontology department, Faculty of Medicine, Ain Shams University, Cairo, Egypt.

2Resident of Geriatrics and Gerontology, Faculty of Medicine, Mansoura University.

\begin{abstract}
Background: Malnutrition is a global health problem especially in extremes of age. Elderly people are a fast-growing group that is at greater risk of malnutrition due to high prevalence of comorbidities and limited resources available for them. Elderly are more prone to negative effects of malnutrition on quality of life and health outcomes due to their vulnerable nature and this is often preventable.
\end{abstract}

Aim: To assess the effect of nutritional status on Health-Related Quality of Life (HRQLL) among community-dwelling elderly living in a rural village in Dakahliya, Egypt.

Methods: A cross-sectional study. A random sample of 170 community-dwelling elderly living in Dakahliya. Demographic data were collected, and comprehensive geriatric assessment was done for each participant including history taking, clinical examination, psychological, mental and functional assessment. Assessment of nutritional status was done using the Mini-Nutritional Assessment (MNA) questionnaire and anthropometric measurements. HRQoL was measured using the Short-Form Health Survey-36 items (SF-36) questionnaire.

Results: The present study showed that among the 170 participants; $45(26.5 \%)$ of them were malnourished, 69 $(40.6 \%)$ were at risk of malnutrition and $56(32.9 \%)$ were well nourished, and showed that HRQoL was significantly poorer in malnourished elderly $(P<0.001)$.

Conclusions: The high prevalence of malnutrition highlights the importance of regular screening of elderly at community settings. As improvement in $\mathrm{HRQoL}$ is a growing goal for the worldwide health care and the strong effect of nutritional status on HRQoL, nutritional screening and intervention are extremely important especially for elderly.

Keywords: Malnutrition, Quality of life, Elderly, Community-dwelling, Egypt.

\section{Background}

World's elderly population is rapidly growing with estimates that the proportion of elderly population over 60 years will double from $11 \%$ to $22 \%$ in the first five decades of $21^{\text {st }}$ century. The absolute number of elderly is expected to triple from 605 million to 2 billion over this period ${ }^{1}$.

Longevity is desirable, but what matters is living with satisfactory Quality of Life (QoL) ${ }^{2}$. QoL is a broad multidimensional concept based on subjective measures of life, while HRQoL is a more specific aspect of QoL that is related to health ${ }^{3}$. Elderly are at greater risk for developing illnesses, that impair HRQoL ${ }^{4}$.

One of possible potentially modifiable determinants of HRQoL is nutrition, because adequate nutrition can delay the age-related frailty and functional dependency by preserving muscle mass and immunity in elderly ${ }^{5}$. Malnutrition is defined as state of deficiency, excess or imbalance of a wide range of nutrients, resulting in significant adverse effects on body structure, function and clinical outcome ${ }^{6}$. The reported prevalence of malnutrition in elderly ranged from $23-60 \%$ and $5-30 \%$ in acute care 7 and community settings respectively.

There are several factors that predispose elderly to malnutrition. This includes physiological, social and economic factors, often referred to as "nine D's" (dysphagia, dysgeusia, dementia, depression, diarrhea, poor dentition, disease, dysfunction and drugs) ${ }^{9}$. 
Malnutrition has been shown to correlate with higher rates of mortality, longer length and increased cost of hospital stay in elderly 10,11. Malnourished elderly have two folds increased risk of long-term mortality ${ }^{12}$ , three times longer length of hospitalization ${ }^{13}$, three times higher risk of infection 11 , higher costs of hospital care ${ }^{14}$, greater likelihood of hospital readmission after discharge 15 , and greater dependence in activities of daily living (ADLs) ${ }^{16}$.

Assessment of nutritional status in elderly could be done through dietary assessment (e.g. 24 hours recall, food frequency questionnaires or diet quality indices) 17-19 , clinical assessment for signs of malnutrition ${ }^{20}$, anthropometric measurements (e.g. Body Mass Index (BMI), mid-arm circumference, tricepital skin fold thickness and Biometric Impedance Analysis (BIA)) ${ }^{21-}$

24 and biochemical markers of malnutrition (e.g. albumin, transferrin, retinol-binding proteins and thyroxine-binding pre-albumin) ${ }^{25}$.

Malnutrition has a deleterious effect on physical, mental and social functions and may reduce functional capacity and therefore HRQoL ${ }^{26}$.

On the other hand, excessive eating and poor physical activity also may impair health and cause mental health problems, especially if obesity occurs 27 .

The relationship between malnutrition and disability are interchanged. Malnourished elderly are at greater risk to be disabled, and disabled elderly are likely to have nutritional abnormalities because of their dependency on the others ${ }^{28}$.

\section{Methods}

170 subjects were chosen through a stratified random sampling from community-dwelling elderly at a rural village (Al-Menyal / Dakahliya / Egypt).

Study was approved by the ethical committee of the Faculty of Medicine, Ain Shams University. Consent was taken from all participants.

All participants were subjected to:

Comprehensive geriatric assessment including complete history taking, clinical examination, mental (MMSE) ${ }^{29}$ , psychological (GDS) ${ }^{30}$ and functional assessment (ADL and IADL) ${ }^{31,32}$.

Nutritional status assessment using MNA, BMI and waist/hip ratio (WHR).

Health related quality of life was measurement using SF-36.

The MNA consists of 18 items including dietary, anthropometrical and subjective measurements. The MNA correlates well with clinical assessment and objective measures of nutritional status (e.g. BMI, energy intake and vitamin intake). MNA is highly validated with scores reaching high levels of sensitivity $(98 \%)$ and specificity $(96 \%)$.

Diagnosis of nutritional status was done using MNA (Identifying those who are malnourished ( $<17$ points) and those who are at risk of malnutrition (17-23.5 points). Subjects with scores (24 points) or more were considered well-nourished ${ }^{33}$.
The SF-36 is a multi-purpose questionnaire that contains 36 questions. Its results are processed into eight-scale profile of scores that reflect eight HRQoL domains (physical functioning, physical limitation, emotional limitation, energy/fatigue, emotional wellbeing, social functioning, pain and general health). It has proven high efficiency in measuring health with subsequent ability to compare different populations, estimating relative burden of various diseases, identifying and comparing the health benefits produced by different treatments and screening individual patients ${ }^{34}$.

WHR was calculated by dividing the waist circumference (midpoint between lower border of costal margin and upper border of iliac crest) by hip circumference (widest portion of buttocks) using stretch-resistant tape. According to World Health Organization (WHO), abdominal obesity is identified by WHR more than 0.85 and 0.9 for females and males respectively 35 .

BMI is used for classification of overweight and obesity in adults. It is defined as individual's weight in kilograms divided by square of height in meters. BMI between 25 and $30 \mathrm{~kg} / \mathrm{m}^{2}$ implies overweight while BMI greater than or equal to $30 \mathrm{~kg} / \mathrm{m}^{2}$ implies obesity, which is further divided into 3 classes ${ }^{36}$.

Participants were then assigned groups according to nutritional status.

\section{Statistical Analysis}

Analysis of data performed by using SPSS package version 15.0.

Description of data in the form of mean (M) and standard deviation (SD) for all quantitative variables and frequency and percentage for all qualitative variables. Comparison of qualitative variables was done using chi-square test (X2). Significance levels measured according to $\mathrm{P}$ value (probability) $\mathrm{P}>0.05$ insignificant, $\quad \mathrm{P}<0.05$ significant, $\mathrm{P}<0.01$ highly significant.

\section{Results}

One hundred and seventy community-dwelling elderly subjects from a rural village at Dakahliya participated in the study. The mean $( \pm S D)$ age of study population was $71.5( \pm 5.4)$ years. Among the 170 participants, $45(26.5 \%)$ of them were malnourished, $69(40.6 \%)$ were at risk of malnutrition and $56(32.9 \%)$ were well nourished; this categorization was done based on MNA (table 1).

Table 1: Mini-nutritional assessment of the studied cases.

\begin{tabular}{|l|l|l|}
\hline Items & N & \% \\
\hline Well nourished & 56 & 32.9 \\
\hline At risk & 69 & 40.6 \\
\hline Malnourished & 45 & 26.5 \\
\hline Total=170 & \multicolumn{2}{|l}{} \\
\hline
\end{tabular}


Hamza SA et al. EJGG.2018; 5(2):12-16

Table 2: Demographic characteristics and relation to nutritional status.

\begin{tabular}{|c|c|c|c|c|c|}
\hline \multirow{2}{*}{\multicolumn{2}{|c|}{ Items }} & \multicolumn{3}{|l|}{ MNA groups } & \multirow{2}{*}{$\mathrm{P}$} \\
\hline & & Well $(\mathrm{N}=56)$ & At risk $(\mathrm{N}=69)$ & Mal. $(\mathrm{N}=45)$ & \\
\hline \multicolumn{2}{|l|}{ Age (years) } & $68.1 \pm 3.2$ & $70.4 \pm 3.3$ & $77.3 \pm 5.5$ & $<0.001^{* \wedge}$ \\
\hline \multirow[t]{2}{*}{ Sex } & Male & $32(57.1 \%)$ & $24(34.8 \%)$ & $15(33.3 \%)$ & \multirow{2}{*}{$0.017 * \#$} \\
\hline & Female & $24(42.9 \%)$ & $45(65.2 \%)$ & $30(66.7 \%)$ & \\
\hline \multirow{2}{*}{$\begin{array}{l}\text { Marital } \\
\text { status }\end{array}$} & Married & $48(85.7 \%)$ & $42(60.9 \%)$ & $11(24.4 \%)$ & \multirow[t]{2}{*}{$<0.001 * \#$} \\
\hline & Widow & $8(14.3 \%)$ & $27(39.1 \%)$ & $34(75.6 \%)$ & \\
\hline \multirow{4}{*}{ Education } & Illiterate & $12(21.4 \%)$ & $52(75.4 \%)$ & $45(100.0 \%)$ & \multirow[t]{4}{*}{$<0.001 * \&$} \\
\hline & Read\& write & $30(53.6 \%)$ & $16(23.2 \%)$ & $0(0.0 \%)$ & \\
\hline & Below high & $9(16.1 \%)$ & $1(1.4 \%)$ & $0(0.0 \%)$ & \\
\hline & High & $5(8.9 \%)$ & $0(0.0 \%)$ & $0(0.0 \%)$ & \\
\hline Residence & With family & & & & \\
\hline \multirow{3}{*}{ Occupation } & Manual & $16(28.6 \%)$ & $22(31.9 \%)$ & $4(8.9 \%)$ & \multirow[t]{3}{*}{$<0.001 * \#$} \\
\hline & Other work & $13(23.2 \%)$ & $2(2.9 \%)$ & $3(6.7 \%)$ & \\
\hline & Not working & $27(48.2 \%)$ & $45(65.2 \%)$ & $38(84.4 \%)$ & \\
\hline \multirow[t]{2}{*}{ Income } & $<1000$ & $7(12.5 \%)$ & $48(69.6 \%)$ & $45(100.0 \%)$ & \multirow[t]{2}{*}{$<0.001 * \#$} \\
\hline & $\geq 1000$ & $49(87.5 \%)$ & $21(30.4 \%)$ & $0(0.0 \%)$ & \\
\hline \multirow[t]{3}{*}{ Smoking } & Current & $16(28.6 \%)$ & $9(13.0 \%)$ & $0(0.0 \%)$ & \multirow[t]{3}{*}{$0.002 * \#$} \\
\hline & Ex-smoker & $7(12.5 \%)$ & $9(13.0 \%)$ & $10(22.2 \%)$ & \\
\hline & Never & $33(58.9 \%)$ & $51(73.9 \%)$ & $35(77.8 \%)$ & \\
\hline \multicolumn{2}{|l|}{ Alcohol } & & & & \\
\hline
\end{tabular}

Table 3: Comparison between MNA groups regarding HRQoL:

\begin{tabular}{|c|c|c|c|c|}
\hline Items & $\begin{array}{l}\text { Well } \\
(N=56)\end{array}$ & $\begin{array}{l}\text { At risk } \\
(N=69)\end{array}$ & $\begin{array}{l}\text { Mal. } \\
(N=45)\end{array}$ & $\mathbf{P}$ \\
\hline Physical function & $79.4 \pm 18.6$ & $78.0 \pm 18.6$ & $37.8 \pm 24.2$ & $<0.001 *$ \\
\hline Physical limitation & $87.5 \pm 16.5$ & $85.9 \pm 18.9$ & $40.6 \pm 32.5$ & $<0.001 *$ \\
\hline Emotional limitation & $97.6 \pm 8.7$ & $85.0 \pm 19.4$ & $12.6 \pm 22.8$ & $<0.001 *$ \\
\hline Energy/fatigue & $93.1 \pm 5.0$ & $75.9 \pm 8.0$ & $35.1 \pm 17.4$ & $<0.001 *$ \\
\hline Emotional well being & $91.0 \pm 5.7$ & $82.1 \pm 11.7$ & $31.8 \pm 16.9$ & $<0.001 *$ \\
\hline Social functioning & $84.6 \pm 12.8$ & $69.7 \pm 16.1$ & $52.8 \pm 13.3$ & $<0.001 *$ \\
\hline Pain & $83.9 \pm 14.8$ & $82.5 \pm 15.6$ & $44.1 \pm 26.5$ & $<0.001 *$ \\
\hline General health & $94.4 \pm 1.7$ & $85.7 \pm 9.0$ & $38.3 \pm 17.6$ & $<0.001 *$ \\
\hline Total & $88.9 \pm 7.5$ & $80.6 \pm 10.7$ & $36.6 \pm 18.6$ & $<0.001 *$ \\
\hline
\end{tabular}

Table 4: Correlation between nutritional indices and other factors::

\begin{tabular}{|c|c|c|c|c|c|c|}
\hline \multirow[t]{2}{*}{ Items } & \multicolumn{2}{|l|}{ BMI } & \multicolumn{2}{|l|}{ MNA } & \multicolumn{2}{|l|}{ WHR } \\
\hline & $\mathbf{R}$ & $\mathbf{P}$ & $\mathbf{R}$ & $\mathbf{P}$ & $\mathbf{R}$ & $\mathbf{P}$ \\
\hline Physical functioning & 0.247 & $<0.001 *$ & 0.630 & $<0.001 *$ & -0.062 & 0.421 \\
\hline Physical limitation & 0.294 & $<0.001 *$ & 0.643 & $<0.001 *$ & -0.008 & 0.915 \\
\hline Emotional limitation & 0.546 & $<0.001 *$ & 0.859 & $<0.001 *$ & 0.253 & $<0.001 *$ \\
\hline Energy/fatigue & 0.620 & $<0.001 *$ & 0.912 & $<0.001 *$ & 0.330 & $<0.001 *$ \\
\hline Emotional Well Being & 0.534 & $<0.001 *$ & 0.858 & $<0.001 *$ & 0.237 & $0.002 *$ \\
\hline Social functioning & 0.500 & $<0.001 *$ & 0.681 & $<0.001 *$ & 0.457 & $<0.001 *$ \\
\hline Pain & 0.283 & $<0.001 *$ & 0.645 & $<0.001 *$ & -0.028 & 0.720 \\
\hline General health & 0.626 & $<0.001 *$ & 0.881 & $<0.001 *$ & 0.333 & $<0.001 *$ \\
\hline Total QoL score & 0.502 & $<0.001 *$ & 0.848 & $<0.001 *$ & 0.197 & $0.010 *$ \\
\hline MMSE & 0.646 & $<0.001 *$ & 0.949 & $<0.001 *$ & 0.405 & $<0.001 *$ \\
\hline $\mathbf{A D L} \mathbf{L}^{\#}$ & 0.664 & $<0.001 *$ & 0.691 & $<0.001^{*}$ & 0.265 & $<0.001 *$ \\
\hline IADL $^{\#}$ & 0.721 & $<0.001 *$ & 0.782 & $<0.001^{*}$ & 0.324 & $<0.001 *$ \\
\hline GDS $^{\#}$ & -0.705 & $<0.001 *$ & -0.880 & $<0.001 *$ & -0.389 & $<0.001 *$ \\
\hline
\end{tabular}


According to univariate analysis on data, a statistically significant relationship $(\mathrm{P}<0.001)$ was found between lower MNA scores and poorer HRQoL (total score and individual domains) (table 3). Table (4) shows significant relationships $(\mathrm{P}<0.001)$ between poor nutritional indices (MNA, BMI and WHR) with risk of depression, cognitive and functional impairment as well as poor HRQoL.

\section{Discussion}

Prevalence of malnutrition among this study is $26.5 \%$ which is higher than the prevalence found in most research in community-dwelling elderly.

Malnutrition was significantly higher in females (30\%) compared to males $(21 \%)$. A systematic review done by van der Pols-Vijlbrief et al., $2014^{37}$ and Donini et al., $20133^{38}$ yielded similar results.

About $(75 \%)$ of malnourished cases were widowed and almost all of malnourished cases were illiterate. Malnutrition was significantly associated with high age (P-value $<0.001)$, low income $(\mathrm{P}$-value $<0.001)$ and unemployment (P-value $<0.001)$.

Maseda et al., $2017 \quad 39$ stressed on the significant correlation between malnutrition and being "widow", it may be attributed to "feeling loneliness" and consequent impaired social resources and poor quality of life. Torres et al., $2014{ }^{40}$ and KrzymińskaSiemaszko et al., $2015^{41}$ also demonstrated that high age, low education and low income are independent effectors on nutritional status.

This study showed that smoking significantly associated with lower risk of malnutrition (Pvalue $=0.002$ ). A study done by Nazemi et al., 2015 noticed a similar relation. This could be explained by the favorable effect of smoking on bowel movements and prevention of constipation. Also, the antalgic effect of smoking and positive effect on mood improve appetite and enhance food intake ${ }^{42}$.

According to this study, significant correlations were found between nutritional status of our sample of community-dwelling elderly living in Dakahliya (both males and females, using MNA) and their HRQoL (using SF-36, total score and individual domains) with P-value $(<0.001)$.

There were no statistically significant differences between scores of 3 domains of HRQoL (physical function, physical limitation and pain) among (wellnourished) and (at-risk) groups compared to (malnourished) group. This denotes that physical and pain aspects of HRQoL tend to fall only with very low level of nutritional status unlike other psychological domains (Emotional well-being and emotional limitation) and social domain (social function) which are more sensitive to state of nutrition.

Research studying the relation between nutritional status and HRQoL found variable degrees of significance. A cross-sectional study done at Norway by Kvamme et al., $2011 \quad{ }^{43}$ including 3286 community-dwelling elderly found a significant association between risk of malnutrition and impaired HRQoL in both men and women (P-value for men $<0.001$ and for women was only 0.02). Elderly men are more prone to malnutrition-related decrease in HRQoL than women.

Another cross-sectional study done at Spain by Jimenez-Redondo et al., $2014 \quad 44$ studied the relationship between nutritional status and HRQoL in elderly (80-90 years old) and nonagenarians ( $>90$ years old). In both groups the relationship was significant ( $\mathrm{P}$ value $=0.012$ ).

A systematic review and meta-analysis of (30) studies by Rasheed et al., $2013{ }^{45}$ addressed the relationship between nutritional status and HRQoL. According to (15) observational studies the relationship was significant (P-value <0.001). The remaining were interventional studies that were concerned with addressing the benefit of nutritional intervention on HRQoL, the results combined for meta-analysis yielded significant results $(\mathrm{P}$-value $=0.002)$.

Our study also demonstrated significant positive associations between cognitive status (using MMSE) and functional level of elderly (using ADL and IADL) with nutritional status using MNA (P-value $<0.001$ ).

Many studies confirmed the strong positive association between nutrition on mental functions and functional level $46-48$

Depression (using GDS) was significantly associated with poor nutrition using MNA (P-value $<0.001)$. Saka et al., $2010 \quad 46$ noted the same relationship between depression and malnutrition using MNA score.

\section{Conclusion:}

Prevalence of malnutrition is high among communitydwelling Egyptian elderly living in Dakahliya. Malnutrition is associated with higher age, female gender, being widow, low income and unemployment. Significant relationships were found between malnutrition with depression, cognitive impairment and functional dependency. Malnutrition was associated with poorer HRQoL among community-dwelling Egyptian elderly.

\section{References}

1. WHO. Facts about ageing 2014; Available from: http://www.who.int/ageing/about/facts/en/.

2. Rennemark, M., et al., Relationships between physical activity and perceived qualities of life in old age. Results of the SNAC study. Aging Ment Health, 2009. 13(1): p. 1-8.

3. $\quad$ CDC, Center for Disease Control and prevention., Measuring healthy days: Population assessment of health-related quality of life. Atlanta: CDC, 2000: p. 4-6.

4. Naseer, M. and C. Fagerstrom, Prevalence and Association of Undernutrition with Quality of Life among Swedish People Aged 60 Years and Above: Results of the SNAC-B Study. J Nutr Health Aging, 2015. 19(10): p. 970-9.

5. Payette, H., Nutrition as a determinant of functional autonomy and quality of life in aging: a research program. Can J Physiol Pharmacol,
2005.
83(11):
1061-70. 
6. Saunders, J., T. Smith, and M. Stroud, Malnutrition and undernutrition. Medicine, 2014. 43(2): p. 112-118.

7. Agarwal, E., et al., Malnutrition in the elderly: A narrative review. Maturitas, 2013. 76(4): p. 296-302

8. Cuervo, M., et al., Nutritional assessment interpretation on 22 007 Spanish community-dwelling elders through the Mini Nutritional Assessment test. Public Health Nutrition, 2009. 12(1): p. 82-90.

9. Edington, J., et al., Prevalence of malnutrition on admission to four hospitals in England. Clinical Nutrition, 2000. 19(3): p. 191-195.

10. Correia, M.I.T., A.C.L. Campos, and E.C. Study, Prevalence of hospital malnutrition in Latin America:: The multicenter ELAN study. Nutrition, 2003. 19(10): p. 823-825.

11. Pirlich, M., et al., The German hospital malnutrition study. Clinical nutrition, 2006. 25(4): p. 563-572.

12. Sullivan, D., et al., The GAIN (Geriatric Anorexia Nutrition) registry: the impact of appetite and weight on mortality in a long-term care population. The journal of nutrition, health \& aging, 2001. 6(4): p. 275-281. 13. Pichard, C., et al., Nutritional assessment: lean body mass depletion at hospital admission is associated with an increased length of stay. The American journal of clinical nutrition, 2004. 79(4): p. 613-618.

14. Chima, C.S., et al., Relationship of nutritional status to length of stay, hospital costs, and discharge status of patients hospitalized in the medicine service. Journal of the American Dietetic Association, 1997. 97(9): p. 975-978.

15. Thomas, D.R., et al., Malnutrition in subacute care. The American journal of clinical nutrition, 2002. 75(2): p. 308-313.

16. Nestle. Malnutrition in the Older Adult. 2010 [cited 2017; Available from: http://www.nestle.com/assetlibrary/documents/library/events/2010-malnutrition-in-olderpeople/factsheet malnutrition e for-web.pdf.

17. Pirlich, M. and H. Lochs, Nutrition in the elderly. Best Pract Res Clin Gastroenterol, 2001. 15(6): p. 869-84.

18. Omran, M.L. and J.E. Morley, Assessment of protein energy malnutrition in older persons, part I: History, examination, body composition, and screening tools. Nutrition, 2000. 16(1): p. 50-63

19. Guerrero, M.L.P. and F. Pérez-Rodríguez, Diet Quality Indices for Nutrition Assessment: Types and Applications, in Functional FoodImprove Health through Adequate Food. 2017, InTech.

20. Adrienne Youdim, M., Nutrition in Clinical Medicine. 2016, Merck Manual of Diagnosis and Therapy.

21. Allard, J.P., et al., Nutrition risk factors for survival in the elderly living in Canadian long-term care facilities. J Am Geriatr Soc, 2004. 52(1): p. 59-65.

22. Stratton, R.J., C.J. Green, and M. Elia, Disease-related malnutrition: an evidence-based approach to treatment. 2003: Cabi.

23. WHO, Measuring obesity : classification and description of anthropometric data : report on a WHO consultation on the epidemiology of obesity, Warsaw, 21-23 October 1987. 1989, [Copenhagen]: World Health Organization, Regional Office for Europe.

24. Suttmann, U., et al., Incidence and prognostic value of malnutrition and wasting in human immunodeficiency virus-infected outpatients. J Acquir Immune Defic Syndr Hum Retrovirol, 1995. 8(3): p. 239-46.

25. Yamada, T., et al., Atlas of Gastroenterology, 4th Edition. 4th ed. 2003: Lippincott Williams \& Wilkins. 1208

26. van der Zwaluw, N.L., et al., The impact of protein supplementation on cognitive performance in frail elderly. European journal of nutrition, 2014. 53(3): p. 803-812.

27. Cheng, F.W., et al., Obesity as a risk factor for developing functional limitation among older adults: A conditional inference tree analysis. Obesity, 2017

28. Maddox, G.L., The encyclopedia of aging: a comprehensive resource in gerontology and geriatrics. 2013: Springer.

29. Folstein, M.F., S.E. Folstein, and P.R. McHugh, "Mini-mental state": a practical method for grading the cognitive state of patients for the clinician. Journal of psychiatric research, 1975. 12(3): p. 189-198.

30. Yesavage, J.A. and J.I. Sheikh, 9/Geriatric depression scale (GDS) recent evidence and development of a shorter version. Clinical gerontologist, 1986. 5(1-2): p. 165-173.

31. Katz, S., et al., Studies of illness in the aged: the index of ADL: a standardized measure of biological and psychosocial function.
Jama, 1963. 185(12): p. 914-919

32. Lawton, M., E. Brody, and U. Médecin, Instrumental activities of daily living (IADL). The Gerontologist, 1969. 9: p. 179-186.

33. Guigoz, Y., B. Vellas, and P.J. Garry, Assessing the nutritional status of the elderly: The Mini Nutritional Assessment as part of the geriatric evaluation. Nutrition reviews, 1996. 54(1): p. S59.

34. Ware, J.E. and B. Gandek, Overview of the SF-36 health survey and the international quality of life assessment (IQOLA) project. Journal of clinical epidemiology, 1998. 51(11): p. 903-912.

35. Organization, W.H., Waist circumference and waist-hip ratio: Report of a WHO expert consultation, Geneva, 8-11 December 2008. 2011.

36. WHO, OBESITY: PREVENTING AND MANAGING THE GLOBAL EPIDEMIC. Report of a WHO Consultation. WHO Technical Report Series 894. 2000: Geneva, Switzerland.

37. van der Pols-Vijlbrief, R., et al., Determinants of proteinenergy malnutrition in community-dwelling older adults: A systematic review of observational studies. Ageing Research Reviews, 2014. 18(Supplement C): p. 112-131.

38. Donini, L.M., et al., Malnutrition in elderly: social and economic determinants. J Nutr Health Aging, 2013. 17(1): p. 9-15.

39. Maseda, A., et al., Quality of life, functional impairment and social factors as determinants of nutritional status in older adults: The VERISAÚDE study. Clinical Nutrition, 2017.

40. Torres, M.J., et al., Nutritional status in community-dwelling elderly in France in urban and rural areas. PloS one, 2014. 9(8): p. e105137.

41. Krzymińska-Siemaszko, R., et al., Social and economic correlates of malnutrition in Polish elderly population: The results of PolSenior study. The journal of nutrition, health \& aging, 2015. 19(4): p. 397-402.

42. Nazemi, L., et al., Malnutrition, Prevalence and Relation to Some Risk Factors among Elderly Residents of Nursing Homes in Tehran, Iran. Iranian Journal of Public Health, 2015. 44(2): p. 218-227.

43. Kvamme, J.M., et al., Risk of malnutrition and health-related quality of life in community-living elderly men and women: the Tromso study. Qual Life Res, 2011. 20(4): p. 575-82.

44. Jimenez-Redondo, S., et al., Influence of nutritional status on health-related quality of life of non-institutionalized older people. J Nutr Health Aging, 2014. 18(4): p. 359-64.

45. Rasheed, S. and R.T. Woods, Malnutrition and quality of life in older people: a systematic review and meta-analysis. Ageing research reviews, 2013. 12(2): p. 561-566.

46. Saka, B., et al., Malnutrition in the elderly and its relationship with other geriatric syndromes. Clinical Nutrition, 2010. 29(6): p. 745-748.

47. Koren-Hakim, T., et al., The relationship between nutritional status of hip fracture operated elderly patients and their functioning, comorbidity and outcome. Clinical nutrition, 2012. 31(6): p. 917-921.

48. Furuta, M., et al., Interrelationship of oral health status, swallowing function, nutritional status, and cognitive ability with activities of daily living in Japanese elderly people receiving home care services due to physical disabilities. Community dentistry and oral epidemiology, 2013. 41(2): p. 173-181. 